\title{
Propuesta de reestructuración académico-administrativa de la Facultad de Educación de la Universidad Surcolombiana
}

(Documento de trabajo)

\author{
AURA ELENA BERNAL DE ROJAS \\ NELSON ERNESTO LOPEZ JIMÉNEZ \\ LUIS EVELIO VANEGAS RUBIO
}

\section{JORGE ELIAS GUEBELLY ORTEGA MIGUEL ÁNGEL TOVAR DUSSAN LINO MUÑOZ BRAVO}

Teniendo como impronta fundamental la seriedad, el respeto a la divergencia y el compromiso derivado de la responsabilidad adquirida, presenta a la comunidad académica de la Facultad de Educación y a la Universidad Surcolombiana, el resultado de su trabajo, advirtiendo que no es un proyecto culminado, toda vez, que se tiene la convicción de que todo proceso de reforma, lejos de ser un documento, es un compromiso de directivos, egresados, docentes, estudiantes, comunidad educativa en general, hacia la consecución de niveles óptimos de calidad y excelencia de los procesos desarrollados de cara a la Misión de la Facultad de Educación.

Aspira a presentar un tratamiento integral del proceso a reestructurar y manifiesta su intención de convertirse en interlocutor legítimo en el proceso de estudio, discusión, análisis y aprobación de la propuesta aquí presentada.

En esta revista nos proponemos dar a conocer lo más fundamental de la propuesta. MISIÓN DE LA FACULTAD DE EDUCACIÓN DE LA UNIVERSIDAD SURCOLOMBIANA 
La Facultad de Educación de la Universidad Surcolombiana tiene como misión formar el recurso profesional docente de la mejor calidad en las diferentes áreas del conocimiento, con un claro sentido humanista e integral; avanzar en la consolidación de un Sistema de Investigación Pedagógica y Educativa, hacia la constitución de nuevos saberes, que sirva para el mejoramiento de la calidad educativa en todos los niveles y modalidades educativas, formal, no formal e informal, de la región surcolombiana, el país y la esfera internacional.

\section{PROPÓSITOS Y OBJETIVOS}

Para dar cumplimiento de su misión la Facultad de Educación, se compromete aFormar desde su particular proyecto académico un educador de la más alta calidad humana, científica y ética.

- Aportar al mejoramiento de la calidad de la educación y a la elevación del nivel intelectual de los docentes para su realización personal, la cualificación del desempeño profesional y su proyección social.

- aviu Propiciar la construcción y fortalecimiento de la pedagogía como saber científico que fundamente la profesionalización del educador.

- Contribuir a la creación de una cultura científica y de una cultura de la solidaridad, de la participación democrática, de la paz y de una cultura de preservación del medio ambiente.

- Fortalecer la investigación pedagógica, disciplinaria e interdisciplinaria, básica y aplicada, y fundamentar la formación académica y profesional en ella.

- Propiciar el proceso de modernización curricular de los diferentes programas de pregrado y postgrado de cara al proceso de acreditación.

- Formar educadores de los niveles de edurcación preescolar, educación básica primaria, educación básica secundaria, educación especial, educación de adultos y etnoeducación y ofrecer la formación pedagógica correspondiente a los egresados de las carreras de ciencias, artes, humanidades y tecnologías que aspiren a desempeñarse como profesores en la educación media y técnica.

- Evaluar la calidad, pertinencia e impacto social de las diferentes estrategias de formación de educadores.

- Desarrollar programas de servicio e investigación que impulsen el mejoramiento de la docencia en todos los niveles de la educación, contribuir al desarrollo de una pedagogia universitaria y adelantar programas de perfeccionamiento y actualización dirigidos a los educadores en servicio de la USCO y de las demás instituciones educativas de la región surcolombiana.

- Propiciar el surgimiento de grupos de trabajo (comunidades académicas y cientificas) y colectivos de docentes que interactuen y se integren con otros grupos a nivel regional, nacional e internacional.

- Contribuir a la consolidación del Sistema Educativo Regional que permita integrar el trabajo interinstitucional e impulse la creación de programas de experimentación pedagógica y de innovación educativa.

- Cooperar con las instituciones regionales y locales que se ocupan de las políticas y programas educativos formales y no formales, así como asesorar científica y técnicamente a las Secretarias de Educación Municipal y Departamental y formular propuestas al ICFES y al Ministerio de Educación Nacional para la elaboración y desarrollo de políticas educativas.

- Introducir e intensificar el uso de las nuevas tecnologías; informática, teleconferencias, acceso a bases nacionales e internacionales de datos.

- Establecer un sistema de publicaciones que promueva la producción intelectual de profesores y estudiantes y facilite la elaboración de material didáctico para los diversos niveles y modalidades del sistema educativo. 
- Crear una cultura académica que induzca al mejoramiento permanente de la calidad de sus programas académicos, la interacción con la comunidad universitaria, una excelencia en el desempeño profesional y un fortalecimiento de la identidad profesional del educador.

- Incluir en la formación de los educadores, la práctica profesional docente integral, mediada por la investigación, como una estrategia de socialización de los educadores en la cultura escolar.

NOTA: La formulación de la misión y los propósitos de la Facultad de Educación fue resultado de la revisión sistemática de la misión de la Universidad Surcolombiana, documentos elaborados por comisiones de reestructuración de las unidades formadoras de docentes, conclusiones de encuentros nacionales y regionales de facultades de educación y algunos documentos sobre la acreditación universitaria, además, de la vivencia y percepción profesional de los autores de este documento, destacando como ejes conceptuales, la relevancia, la significación y la viabilidad de la propuesta formulada.

\section{EXPLICACIONES PERTINENTES EN TORNO A LA ESTRUCTURA ORGÁNICA PROPUESTA}

Importante señalar que la misión y los propósitos de la Facultad de Educación definidos en el numeral anterior, son los puntos de referencia básicos para la elaboración de esta propuesta.

Cada una de las unidades que la integran, responden a exigencias legales y a procesos significativos de la vida universitaria, procurando garantizar una UNIDAD dentro de la diversidad, en procura de una consistencia conceptual y metodológica de la propuesta.

Se entiende por Facultad, la unidad académica administrativa que interrelaciona áreas afines del saber, agrupa profesores y estudiantes para la función integral académico profesional y organiza los currículos para el otorgamiento de títulos académicos y profesionales.

EL INSTITUTO es una unidad caracterizada por su función investigativa y a través de ella, por la de servicio de la Unidad a la comunidad, y de manera ocasional a la docencia tanto a nivel de pregrado y fundamentalmente de postgrado. EL INSTITUTO se propone como objetivo primordial, más que una ciencia o disciplina concreta, un ámbito o campo epistemológico aplicado al enjambre de ciencias y profesiones con algún programa o actividad social. La docencia cuando se da en los Institutos, es de orden práctico y de entrenamiento con participación auxiliar de estudiantes de postgrado, el Instituto no tiene currículos, ni otorga títulos.

LOS INSTITUTOS suelen tener sus propias normas de funcionamiento administrativo y financiero, tienen su propio cuerpo directivo- Un Director y un Comité Asesor o Consultivo- su propia planta física, sus ingresos y su propio presupuesto.

LOS CENTROS, unidad que se encarga fundamentalmente del desarrollo de actividades de extensión universitaria, los Centros a diferencia de los Institutos, intensifican menos la labor investigativa y regularizan en cambio, algunas actividades docentes próximas a la apertura de la educación no formal desligada de los procesos curriculares que la Universidad de ordinario ofrece.

El Centro permite la convergencia de la Universidad en busca de servicios específicos, y también la divergencia para difundirlos fuera de ella. Los Centros gozan de la misma autonomía propia de los Institutos.

DEPARTAMENTO, agrupación de profesores y estudiantes cuya responsabilidad está definida por la docencia, la investigación y el servicio en una línea del conocimiento.

PROGRAMA es el equivalente al currículo que se cursa por norma general en una Facultad y que conduce a la obtención de título académico o profesional. Es temporal 
y puede adelantarse en los diferentes niveles y modalidades de la Educación Superior. SECCION es equivalente a División, componente organizativo para la ejecución de la gestión por razones de funciones de eficacia y responsabilidad.

NOTA: Para avanzar en la precisión conceptual de las anteriores UNIDADES académico-administrativas, se tomó como base el texto "LA ADMINISTRACION DE LAS ESTRUCTURAS ACADEMICAS UNIVERSITARIAS, elaborado por Alfonso Borrero Cabal en el marco del Seminario Permanente sobre Universidad ASCUNICFES, documentos 21 y 22 , promoción 1990 '1992.
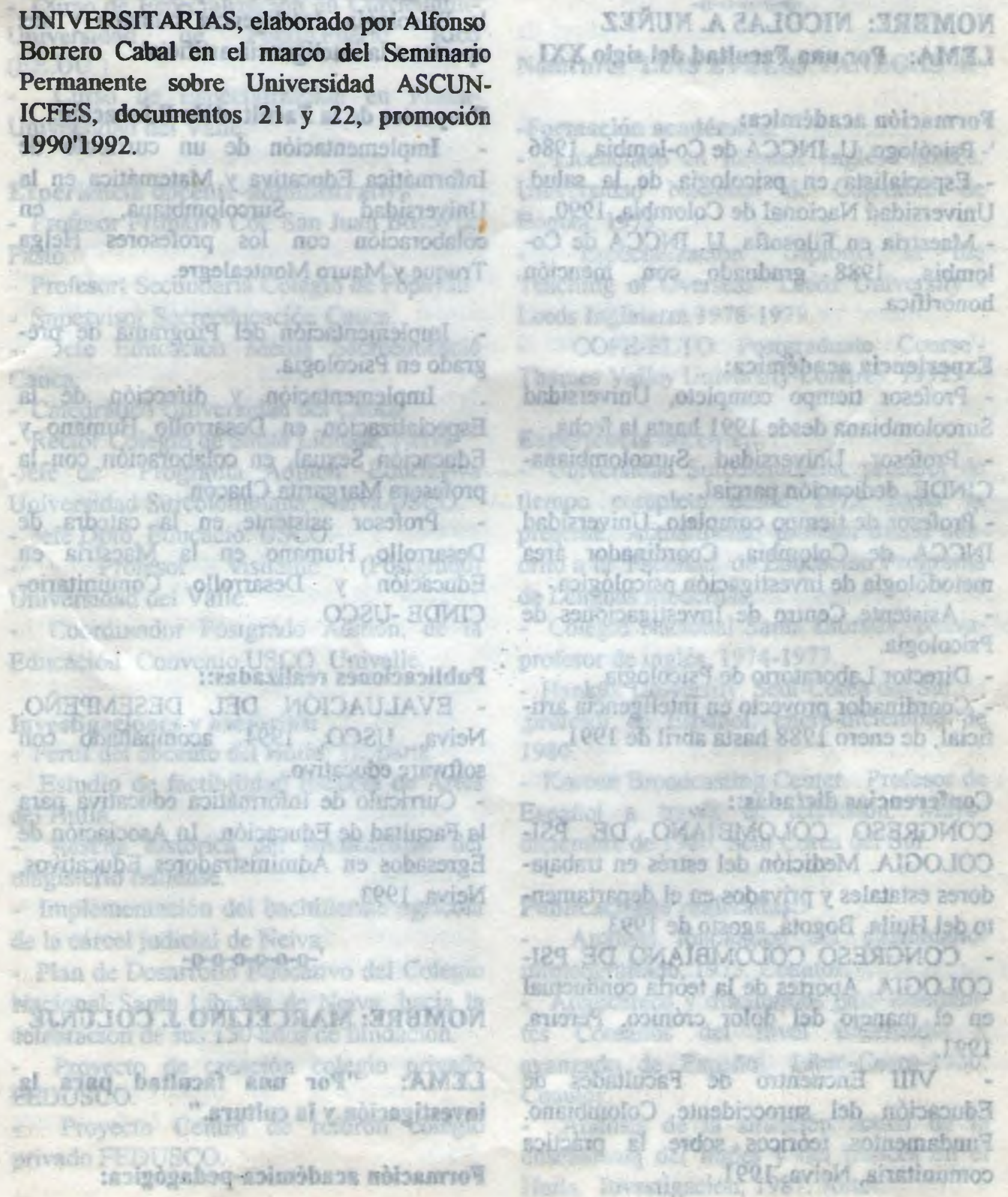